\title{
ASSESSMENT OF INTERATRIAL DYSSYNCHRONY BY TISSUE DOPPLER IMAGING IN MITRAL STENOSIS: EFFECT OF AFTERLOAD REDUCTION AFTER BALLOON MITRAL VALVULOPLASTY.
}

\author{
Aly Saad MBBCh, MSc, MD, FESC ${ }^{1}$; Khalid M. Abd El-Salam MD ${ }^{2}$; Manar Mostafa Elzaki MD ${ }^{3}$ and \\ Rehab Mahmoud Al-Ashry MSc ${ }^{4 *}$ \\ Cardiology Department, Faculty of Medicine, Zagazig University.
}

\begin{abstract}
Background: Atrial fibrillation (AF) predisposition in mitral stenosis (MS) has been studied using many electrocardiographic (increased P-wave dispersion) and echocardiographic parameters (interatrial electromechanical delay). There are scarce data on the effect of percutaneous balloon mitral valvuloplasty (PBMV) on the interatrial electromechanical coupling in patients with MS. We aimed to assess the interatrial electromechanical coupling in MS before and after PBMV by tissue Doppler imaging (TDI) echocardiography.
\end{abstract}

Patients and methods: This study included 45 patients suffered from moderate to severe MS who underwent PBMV successfully without complication and 20 healthy volunteers as a control group. We compared between both groups in the clinical, electrocardiographic and echocardiographic parameters. The patients with MS were re-evaluated one week after PBMV. Interatrial electromechanical delay (EMD) was estimated by TDI before and after PBMV and we compared the results.

Results: The interatrial EMD (56.4 \pm 15.8 vs. $34.6 \pm 7.2 \mathrm{~ms}, p<0.001)$ was higher in patients with MS as compared to healthy individuals. The maximum P-wave duration (P-max) and P-wave dispersion (PWD) showed highly significant positive correlation with the interatrial EMD $(r=0.37, p<0.001$ and $r=0.41, p<$ 0.001 respectively). There was a highly significant decrease in the interatrial EMD (56.4 \pm 15.8 vs. $38.3 \pm$ $10.4 \mathrm{~ms}, p<0.001$ ) one week after PBMV.

Conclusion: The current study showed significant increase in the interatrial EMD in patients with moderate to severe MS. These changes improved significantly after PBMV.

Keywords: Mitral stenosis; Atrial fibrillation; Tissue Doppler imaging; Interatrial electromechanical delay; Percutaneous Balloon Mitral Valvuloplasty.

Abbreviations: $\boldsymbol{A}^{\prime}$ wave: Peak late annular velocity by TDI; $\boldsymbol{A F}$ : Atrial fibrillation; $\boldsymbol{B S A}$ : Body surface area; LA: Left atrium; $L A A$ : Left atrial area; $L A D$ : Left atrial dimension; $L A E F$ : Left atrial ejection fraction; LAEI: Left atrial expansion index; $\boldsymbol{L} A V$ : Left atrial volume; $\boldsymbol{M S}$ : Mitral stenosis; $\boldsymbol{M V}$ : Mitral valve; $\boldsymbol{M V A}$ : Mitral valve area; $\boldsymbol{P}-A^{\prime}$ : The time interval calculated from the beginning of $\mathrm{P}$ wave on the ECG until the beginning of the late diastolic wave at the lateral border of the annulus measured by TDI; PBMV: Percutaneous balloon mitral valvuloplasty; $\boldsymbol{P}$-max: Maximal duration of P-wave; $\boldsymbol{P}$-min: Minimal duration of P-wave; $\boldsymbol{P} W D$ : P-wave dispersion; SPAP: Systolic pulmonary artery pressure; $\boldsymbol{T} D I$ : Tissue Doppler imaging.

\section{INTRODUCTION}

I nteratrial electromechanical abnormalities have been studied as risk of atrial fibrillation (AF) ${ }^{[1,}$ ${ }^{2]}$. Özer et al, ${ }^{[3]}$ used tissue Doppler imaging (TDI) and surface ECG to show interatrial electromechanical delay (EMD) in patients suffered from mitral stenosis (MS). Percutaneous balloon mitral valvuloplasty (PBMV) has become the treatment of choice for isolated, uncomplicated MS with suitable morphology ${ }^{[4]}$. The objectives of this procedure are to increase the mitral valve area and simultaneously to reduce the pressure gradient across it, also to reduce the left atrial pressure and mean pulmonary artery pressure ${ }^{[5,6]}$. Interatrial EMD can be calculated from the difference between the P-A' (lateral mitral) and P-A' (Tricuspid) time intervals [ $\mathrm{PA}^{\prime}$ is the time interval calculated from the beginning of $\mathrm{P}$ wave on the ECG until the beginning of the late diastolic $\mathrm{A}^{\prime}$ wave at the lateral border of the annulus measured by TDI] ${ }^{[3]}$.

\subsection{AIM OF THE WORK}

We aimed to assess the interatrial electromechanical coupling by tissue Doppler imaging (TDI) echocardiography in MS before and after PBMV.

\section{PATIENTS AND METHODS}

The study conducted in Cardiology department, faculty of medicine, Zagazig University from August 2010 to March 2014, it included 65 subjects; 17 males, 48 females who were divided into 2 groups: Group I (Rheumatic Mitral Stenosis group): includes 45 patients; (33 females and 12 males, aged $30.1 \pm 8.99$ years, with a mean mitral valve area (MVA) of $0.99 \pm$ $0.15 \mathrm{~cm}^{2}$ ) who underwent successful PBMV without complications and Group II (Control 
group): includes 20 healthy volunteers (15 females and 5 males, aged $30.6 \pm 7.8$ years). The Group II did not have any known cardiovascular disease or risk factors. All patients with MS were New York Heart Association class $\geq$ II and were eligible for PBMV. The patients with left ventricular dysfunction, hypertension, diabetes mellitus, left ventricular hypertrophy, coronary artery disease, significant pulmonary disease, or additional moderate or severe valvular heart disorders; except secondary tricuspid regurgitation; were excluded from the study. All patients were in sinus rhythm during evaluation. The study patients underwent comprehensive echocardiographic examinations one day before and one week after PBMV. Mitral valve anatomy was scored according to the Wilkins echo scoring system ${ }^{[7]}$. After excluding the contraindications for the procedure with transthoracic and transesophageal echocardiography, PBMV was performed. Also 12-lead ECGs were recorded for each study patient one day before and one week after PBMV. The study protocol was approved by the institutional ethics committee and all patients gave informed consent.

\subsection{Echocardiography}

All echocardiographic examinations were performed with the VIVID 9 ultrasound system (GE, Horten, Norway) using 2.5-3.5 $\mathrm{MHz}$ transducers. Additional to standard M-mode, twodimensional and Doppler measurements evaluating cardiac chambers and the severity of MS and TDI were used. During echocardiographic evaluation a continuous onelead ECG recording was provided. Measurements were obtained from the average of three cardiac cycles. Left ventricle (LV) end-diastolic, endsystolic diameters and left atrial (LA) end-systolic diameter were measured with $\mathrm{M}$-mode in the parasternal long axis view according to American Society of Echocardiography guidelines. MVA was calculated using the planimetry method in the short axis of parasternal view. From the apical four-chamber view, peak and mean trans-mitral gradients in ( $\mathrm{mmHg}$ ) were measured by using continuous wave Doppler echocardiography according to the modified Bernoulli equitation. Systolic pulmonary artery pressure (SPAP) was obtained from the peak continuous wave Doppler signal of tricuspid regurgitaion jet velocity and adding the estimated right atrial pressure to this value. We used the Simpson's biplane modified method for LA volume estimation. The LA volume index was calculated by dividing the LA volume by body surface area. LA ejection fraction $(\mathrm{LAEF})$ defined as $\left.\left(\mathrm{V}_{\max }-\mathrm{V}_{\text {min }}\right) / \mathrm{V}_{\text {max }} \times 100 \%\right)$
${ }^{[8-10]}$. LA expansion index (LAEI) defined as (V $\left.\left.\max -\mathrm{V}_{\min }\right) / \mathrm{V}_{\min } \times 100 \%\right)^{[8-10]}$.

TDI echocardiography was performed using the transducer frequencies of $3.5-4.0 \mathrm{MHz}$ by setting the spectral pulsed Doppler signal filters until a Nyquist limit of $15-20 \mathrm{~cm} / \mathrm{s}$ was reached and the minimal optimal gain was used. The monitor sweep speed was made at $100 \mathrm{~mm} / \mathrm{s}$. In the apical four-chamber view, the pulsed Doppler sample volume was put on the lateral mitral annulus and tricuspid annulus. The time interval calculated from the beginning of $\mathrm{P}$ wave on the ECG until the beginning of the late diastolic wave at the lateral border of the annulus measured by TDI, which was termed $\mathrm{PA}^{\prime}$, was measured from lateral mitral annulus (lateral $\mathrm{PA}^{\prime}$ ) and tricuspid annulus (tricuspid $\mathrm{PA}^{\prime}$ ) Figure (1). The time resulted from subtracting both lateral mitral $\mathrm{PA}^{\prime}$ and tricuspid $\mathrm{PA}^{\prime}$ was defined as interatrial electromechanical delay (EMD) ${ }^{[11]}$.

\subsection{Twelve-lead ECG}

Twelve-lead ECGs were recorded at a rate of $25 \mathrm{~mm} / \mathrm{s}$ in a supine position. P-wave duration was measured from the onset to the offset of $\mathrm{P}$ wave. The measurements were made using a digital caliper and magnifying lens in order to improve accuracy. Maximum and minimum Pwave durations were determined from 12-lead ECGs. Subsequently, P-wave dispersion (PWD) was defined as the difference between maximum $\mathrm{P}$-wave and minimum $\mathrm{P}$-wave duration ${ }^{[11]}$.

\subsection{Percutaneous balloon mitral valvuloplasty}

PBMV indications were: symptomatic patients suffered from moderate to severe MS with favorable valve morphology and asymptomatic patients suffered from moderate to severe MS having pulmonary hypertension (SPAP $\geq 50$ $\mathrm{mmHg}$ at rest or $60 \mathrm{mmHg}$ with exercise) with favorable valve morphology ${ }^{[11]}$.

Before PBMV, all patients were evaluated by transthoracic and trans-esophageal echocardiography in order to exclude the contraindications of the procedure such as moderate or severe mitral regurgitation, severe or bi-commissural calcification and presence of LA thrombus ${ }^{[11]}$.

An experienced cardiologist performed all PBMV procedures via a double-balloon, multitrack technique in a fasting state utilizing percutaneous trans-femoral approach. Standard hemodynamic measurements of right and left heart pressures were evaluated during the procedure $^{[12]}$.

\subsection{Statistical Analysis}

Data checked, entered and analyzed by SPSS version 20. Data were expressed as mean \pm SD for 
quantitative values, numbers and percentage for categorical variables. ANOVA (f test), paired-t test, Chi-square $\left(\mathrm{x}^{2}\right)$ and Pearson's' correlation $r$ were used when appropriate. We considered results statistically significant when $p$ value $\leq$ 0.05 .
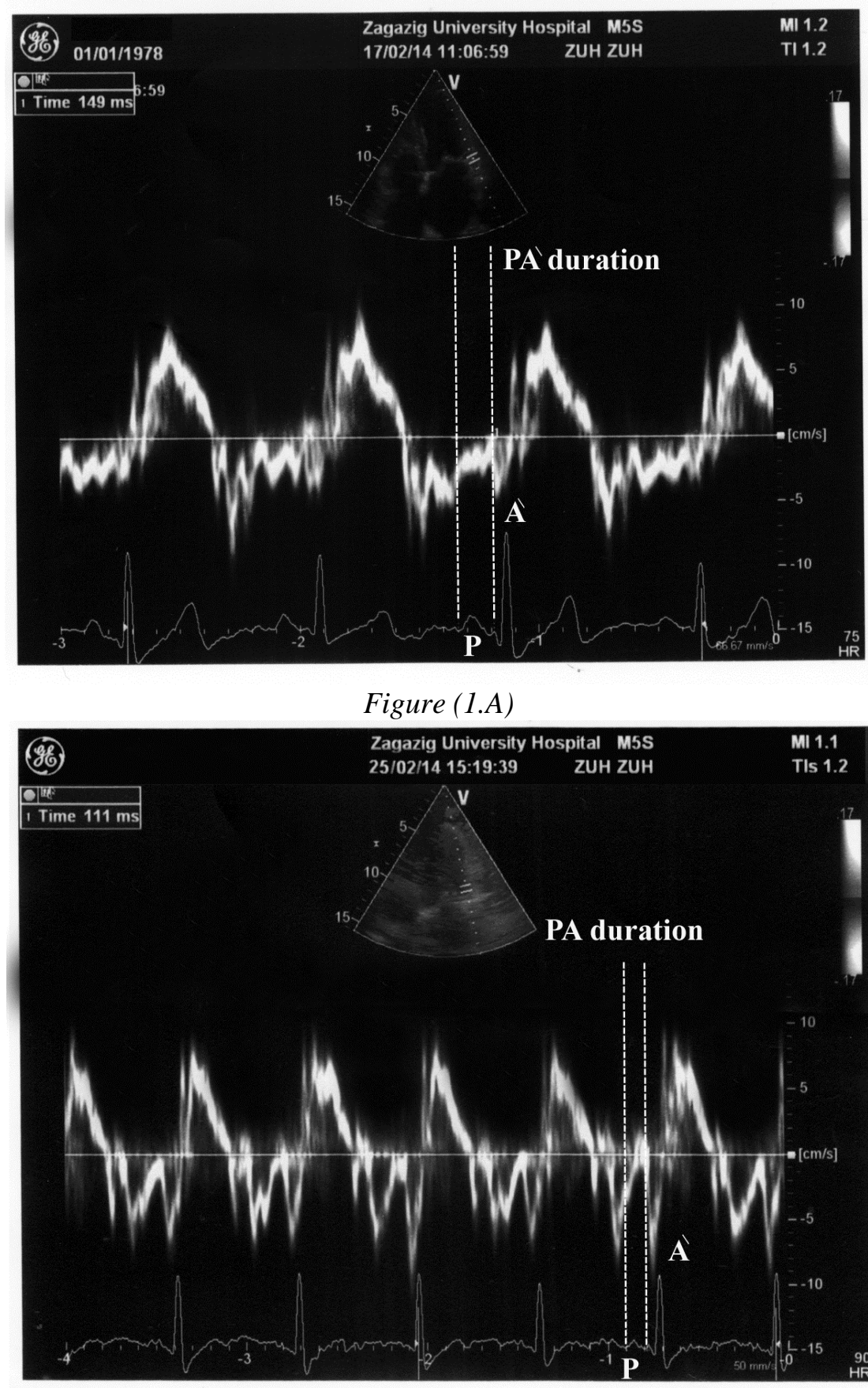

Figure (1.B)

Figure (1): Improvement of TDI PA'measured at the lateral mitral annulus, Figure (1.A) measured before PBMV and Figure (1.B) measured one week after the procedure.

\section{RESULTS}

The baseline demographic, clinical, echocardiographic and electrocardiographic parameters of Group I and Group II are shown in Table (1). There were no significant differences between Group I and Group II as regard age, gender, body surface area, blood pressure, LV end systolic diameter (LVESD) and LV function ( $p>$
0.05). The LA diameter, LA volume, LA volume index and a lateral mitral $\mathrm{PA}^{\prime}$ values were highly significant increase in Group I $(p<0.001)$, but LAEF and LAEI were highly significant decrease in Group I $(p<0.05)$ as compared to Group II. Interatrial EMD was also highly significant longer in Group I as compared to Group II $(p<0.001)$. Group I showed highly significant increase in 
both P-max duration and PWD compared to Group II $(p<0.001)$. But, there was no statistical difference between the two groups regarding minimal $\mathrm{P}$-wave duration (P-min.) $(p>0.05)$.

Table (1): The clinical, echocardiographic and electrocardiographic parameters of the studied groups:

\begin{tabular}{|c|c|c|c|c|}
\hline & & $\begin{array}{c}\text { Group I } \\
\text { (MS) } \\
(\mathrm{n}=45)\end{array}$ & $\begin{array}{c}\text { Group II } \\
\text { (Control) } \\
(\mathrm{n}=20)\end{array}$ & $p$-Value \\
\hline \multicolumn{2}{|l|}{$\overline{\text { Age (years) }}$} & $30.1 \pm 8.99$ & $30.6 \pm 7.8$ & $>0.05$ \\
\hline \multirow{2}{*}{ Gender (n \%) } & Male & $12(26.7 \%)$ & $5(25 \%)$ & $>0.05$ \\
\hline & Female & $33(73.3 \%)$ & $15(75 \%)$ & \\
\hline \multicolumn{2}{|l|}{ BSA } & $1.72 \pm 0.1$ & $1.71 \pm 0.1$ & $>0.05$ \\
\hline \multicolumn{2}{|c|}{ Systolic BP (mmHg) } & $115.7 \pm 8.4$ & $114.5 \pm 6.7$ & $>0.05$ \\
\hline \multicolumn{2}{|c|}{ Diastolic BP (mmHg) } & $68.8 \pm 6.4$ & $71.2 \pm 7.4$ & $>0.05$ \\
\hline \multicolumn{2}{|c|}{ HR (beats/min) } & $79 \pm 9.8$ & $76.2 \pm 6.5$ & $>0.05$ \\
\hline \multicolumn{2}{|l|}{ LVEDD (mm.) } & $46.1 \pm 5.3$ & $41.5 \pm 4.4$ & $<0.001$ \\
\hline \multicolumn{2}{|l|}{ LVESD (mm.) } & $28.8 \pm 4.2$ & $26.8 \pm 3.3$ & $>0.05$ \\
\hline \multicolumn{2}{|l|}{ IVST (mm.) } & $9.25 \pm 0.8$ & $8.8 \pm 0.9$ & $>0.05$ \\
\hline \multicolumn{2}{|l|}{ PWT (mm.) } & $8.95 \pm 1$ & $8.56 \pm 1$ & $>0.05$ \\
\hline \multicolumn{2}{|l|}{ EF (\%) } & $67.2 \pm 5.76$ & $65.9 \pm 3.8$ & $>0.05$ \\
\hline \multicolumn{2}{|l|}{ LAD (mm.) } & $47 \pm 3.7$ & $30.4 \pm 3.6$ & $<0.001$ \\
\hline \multicolumn{2}{|l|}{$\mathbf{L A V} V_{\max }(\mathbf{m l})$} & $109.7 \pm 29.8$ & $41.7 \pm 6.9$ & $<0.001$ \\
\hline \multicolumn{2}{|c|}{ Ind. $\mathbf{L A V}$ max $\left(\mathrm{ml} / \mathrm{m}^{2}\right)$} & $63.8 \pm 16.96$ & $24.4 \pm 4.5$ & $<0.001$ \\
\hline \multicolumn{2}{|c|}{ LAEF $(\%)$} & $30.9 \pm 7.7$ & $49.3 \pm 6.2$ & $<0.001$ \\
\hline \multicolumn{2}{|l|}{ LAEI (\%) } & $46 \pm 19.3$ & $104.1 \pm 34.9$ & $<0.001$ \\
\hline \multicolumn{2}{|c|}{ Lateral mitral annulus $\mathbf{P}-\mathrm{A}^{\prime}$ (ms) } & $117.9 \pm 16.7$ & $87.9 \pm 7.5$ & $<0.001$ \\
\hline \multicolumn{2}{|c|}{ Tricuspid annulus $\mathbf{P}-\mathrm{A}^{\prime}$ (ms) } & $60.8 \pm 10$ & $53.3 \pm 53$ & $>0.05$ \\
\hline \multicolumn{2}{|c|}{ Interatrial EMD (ms) } & $56.4 \pm 15.8$ & $34.6 \pm 7.2$ & $<0.001$ \\
\hline \multirow[t]{3}{*}{ ECG findings } & P-max (ms) & $137.4 \pm 12.1$ & $102.4 \pm 6.1$ & $<0.001$ \\
\hline & P-min (ms) & $72 \pm 12.9$ & $77.7 \pm 4.1$ & $>0.05$ \\
\hline & PWD (ms) & $64.4 \pm 13.5$ & $24.6 \pm 4.7$ & $<0.001$ \\
\hline
\end{tabular}

BP: Blood pressure, BSA: Body Surface Area, HR: Heart rate, $\boldsymbol{E F}$ : Ejection fraction, $\boldsymbol{E M D :}$ Electromechanical delay, IVST: Inter-ventricular septum thickness, LAD: Left atrial diameter, $\boldsymbol{L A E F}:$ Left atrial ejection fraction, LAEI: Left atrial expansion index, $\mathbf{L A V}$ : Left atrial volume, LVEDD: left ventricle end diastolic diameter, LVESD: left ventricle end systolic diameter, $\boldsymbol{P}-\boldsymbol{A}^{\prime}$ : The time interval calculated from the beginning of $P$ wave on the ECG until the beginning of the late diastolic wave at the lateral border of the annulus measured by TDI, P-max: Maximal duration of $P$ wave, $\boldsymbol{P}$-min: Minimal duration of $P$-wave, $\boldsymbol{P W D :}$ $P$-wave dispersion, $\boldsymbol{P W T}$ : posterior wall thickness.

A comparison of changes in electrocardiographic and echocardiographic parameters in Group I before and after PBMV is shown in Table (2). One week after PBMV, our study showed highly significant increase in MVA, LAEF and LAEI. But we found highly significant decrease in trans-mitral mean gradient, LA diameter, both LA volume and volume indices and pulmonary artery pressure. Accompanying these hemodynamic effects of the procedure, the ECG parameters of P-max duration and PWD showed a highly significant decrease one week after PBMV $(p<0.001)$. However, the procedure had no significant effect on minimum P-wave duration $(p>0.05)$. Lateral mitral $\mathrm{PA}^{\prime}$ values showed highly significant decrease after PBMV ( $p$ $<0.001)$ but tricuspid $\mathrm{PA}^{\prime}$ interval was statistically not affected by the procedure $(p>$ 0.05). In addition, interatrial EMD was highly significantly improved as compared to previous values $(p<0.001)$. 
Table (2): The effects of PBMV on echocardiographic and electrocardiographic parameters:

\begin{tabular}{|c|c|c|c|}
\hline & $\begin{array}{c}\text { Group I } \\
\text { Before PBMV }\end{array}$ & $\begin{array}{c}\text { Group I } \\
\text { After PBMV }\end{array}$ & $p$-Value \\
\hline $\operatorname{MVA}\left(\mathrm{cm}^{2}\right)$ & $0.99 \pm 0.15$ & $1.88 \pm 0.2$ & $<0.001$ \\
\hline Mean trans-mitral gradient $(\mathbf{m m H g})$ & $15.4 \pm 3.55$ & $5 \pm 1.5$ & $<0.001$ \\
\hline SPAP (mmHg) & $56.7 \pm 12.5$ & $35.9 \pm 5.2$ & $<0.001$ \\
\hline MVA PHT $\left(\mathrm{cm}^{2}\right)$ & $1.05 \pm 0.16$ & $1.89 \pm 0.2$ & $<0.001$ \\
\hline LAD (mm.) & $47 \pm 3.7$ & $41.5 \pm 3.02$ & $<0.001$ \\
\hline $\mathbf{L A V} \mathbf{m a x}_{\text {max }}(\mathbf{m l})$ & $109.7 \pm 29.8$ & $86.4 \pm 26.2$ & $<0.001$ \\
\hline Ind. LAV $\max \left(\mathrm{ml} / \mathbf{m}^{2}\right)$ & $63.8 \pm 16.96$ & $49.9 \pm 14.8$ & $<0.001$ \\
\hline LAEF (\%) & $30.9 \pm 7.7$ & $43.4 \pm 5.4$ & $<0.001$ \\
\hline LAEI (\%) & $46 \pm 19.3$ & $78.6 \pm 17.4$ & $<0.001$ \\
\hline Lateral mitral annulus P-A' (ms) & $117.9 \pm 16.7$ & $95.9 \pm 12.7$ & $<0.001$ \\
\hline Tricuspid annulus $\mathbf{P}-\mathbf{A}^{\prime}$ (ms) & $60.8 \pm 10$ & $57.2 \pm 10.9$ & $>0.05$ \\
\hline Interatrial EMD (ms) & $56.4 \pm 15.8$ & $38.3 \pm 10.4$ & $<0.001$ \\
\hline \multirow[t]{3}{*}{ ECG findings } & $137.4 \pm 12.1$ & $115.6 \pm 13$ & $<0.001$ \\
\hline & $72 \pm 12.9$ & $71.7 \pm 12.2$ & $>0.05$ \\
\hline & $64.4 \pm 13.5$ & $47.4 \pm 12.6$ & $<0.001$ \\
\hline
\end{tabular}

MVA: Mitral valve area, SPAP: Systolic pulmonary artery pressure.

In correlation analysis, a highly significant positive correlation was detected between interatrial EMD and P-max duration $(r=0.37, p<$ $0.001)$ and PWD $(r=0.41, p<0.001)$ Figure (2) and Figure (3) respectively.
The LA diameter, LAV max $_{\text {ax }}$ and. LAV max $_{\text {m }}$ positively associated with interatrial EMD $(r=$ $0.31, p<0.05 ; r=0.33, p<0.05$ and $r=0.33, p<$ 0.05 , respectively) Table (3).

Table (3): Pearson's correlations between interatrial EMD and other ECG and Echocardiographic parameters in the Group I:

\begin{tabular}{lll}
\hline & $\boldsymbol{R}$ & $\boldsymbol{p}$-Value \\
\hline P-max & 0.37 & $<0.001(\mathrm{HS})$ \\
PWD & 0.41 & $<0.001(\mathrm{HS})$ \\
LAD & 0.31 & $<0.05(\mathrm{~S})$ \\
LAV $_{\text {max }}$ & 0.33 & $<0.05(\mathrm{~S})$ \\
Ind. LAV $_{\text {max }}$ & 0.33 & $<0.05(\mathrm{~S})$ \\
\hline
\end{tabular}

Ind. LAV $\boldsymbol{V}_{\text {max }}$ : Maximal Left atrial volume indexed to BSA; LAD: Left atrial dimension;

P-max: Maximal P-wave duration; PWD: P-wave dispersion.

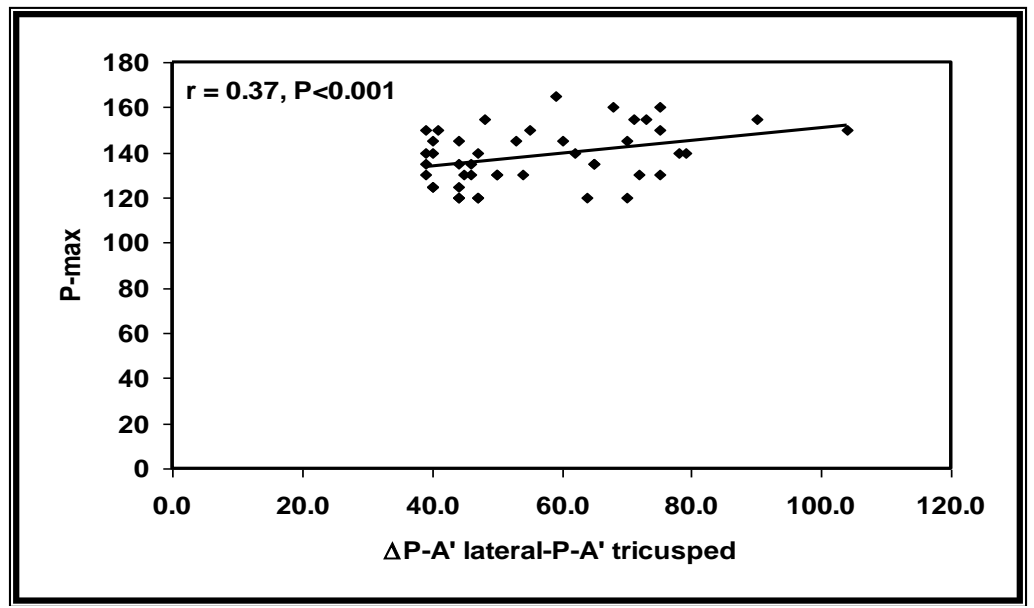

Figure (2): Pearson's correlation between interatrial EMD and P-max in MS group.

$\Delta$ Lateral P-A' - Tricuspid P-A' (ms): Calculated by subtracting the $P-A^{\prime}$ (Tricuspid) from $P-A^{\prime}$ (lateral mitral). 


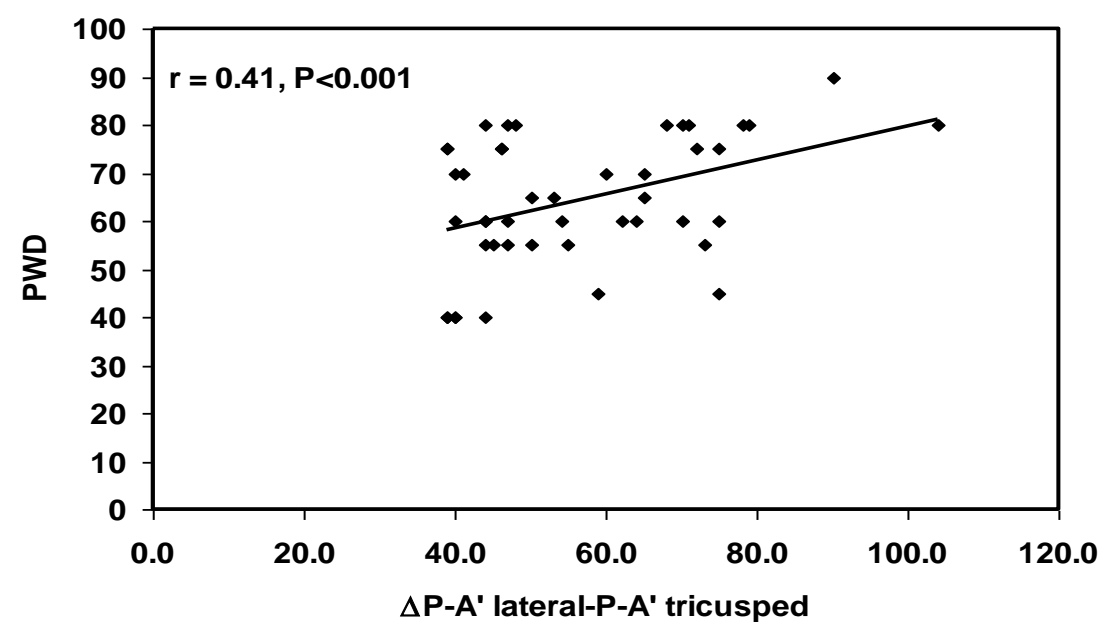

Figure (3): Pearson's correlation between interatrial EMD and PWD in MS group.

$\Delta$ Lateral P-A'- Tricuspid P-A' (ms): Calculated by subtracting the P-A' (Tricuspid) from P-A' (lateral mitral).

\section{DISSCUSSION}

Patients with mitral valve disease frequently presented with atrial conduction disorders. Atrial conduction abnormalities lead to electrophysiological and electromechanical abnormalities which are associated with a higher risk of $\mathrm{AF}{ }^{[13]}$. Both the hemodynamic changes that result in increased LA pressure and volume and the fibrotic process impairing atrial conduction are reported to be related to the higher risk of $\mathrm{AF}$ in these patients ${ }^{[14]}$.

TDI is a technology that allows direct and non-invasive measurement of myocardial velocities ${ }^{[15]}$. Atrial electromechanical delay is evaluated by TDI, a relatively novel noninvasive method for assessing atrial conduction time ${ }^{[16]}$.

This study aimed to assess the interatrial electromechanical coupling by TDI in mitral stenosis before and after PBMV. We included 45 patients with MS with mean MVA $0.99 \pm 0.15$ $\mathrm{cm}^{2}$, who underwent PBMV with improved MVA $\left(1.89 \pm 0.2 \mathrm{~cm}^{2}\right)$ and a control group including 20 healthy individuals. All were examined by TTE with TDI to measure the electromechanical coupling.

We found highly significant increase in both P-max and PWD in MS group compared to control group $(p<0.001)$.

Our findings are in agreement with Krishnamoorthy and colleagues, ${ }^{[17]}$ who demonstrated that P-max and PWD increased in patients with MS and attributed this to LA hypertension that caused LA dilatation, fibrosis, and electrical inhomogeneity.

Concerning the echocardiographic parameters, our results showed the highly significant increase in LAD and both maximal and minimal left atrial area in patient group when compared to the control group $(p<0.001)$.

These findings are in agreement with the results of Özer et al, ${ }^{[3]}$ who stated that LA area and size increase in MS patients compared to the control groups. The cardiac impulse pathway will increase due to the increase in LA size. So, the interatrial EMD will increase.

Krasuski et al, ${ }^{[18]}$ correlated the development of AF to the severity of MS, LA pressure and also to the degree of LA enlargement. In a dilated LA, the time interval for impulse conduction will be longer. In addition to LA enlargement, loss of atrial myocytes and ongoing interstitial fibrosis results in electrical remodeling characterized by inhomogeneous electrical properties and abnormalities in conduction velocity ${ }^{[19]}$.

Our results regarding left atrial indices, showed highly significant decrease in LAEF and LAEI in MS group compared to control group ( $p$ $<0.001$ ). These may lead to impairment of LA reservoir function in MS patients by using both previous indices. These indices are analogous to the LA diastolic function. The dysfunction of LA reservoir property, which reflects "diastolic" LA dysfunction, is likely to occur prior to booster dysfunction of LA, which represents LA "systolic" dysfunction [20]. Dysfunction of LA may lead to intra-atrial stasis associated with spontaneous dense contrast inducing thrombogenesis and causing $\mathrm{AF}^{[21]}$.

We calculated LAEF and LAEI from LA volumes as these parameters can be more reliable of $\mathrm{AF}$ prediction and other cardiovascular disorders than LAD. These results come in 
agreement with Tsang et al, ${ }^{[22,23]}$ who suggested that LA volumes may have more sensitivity to LA remodeling occurrence than LAD.

The pathophysiological role of the mechanical (valvular) and myocardial factors in LA dysfunction due to rheumatic MS is controversial. The inflammatory process due to acute rheumatic fever could affect the myocardium to varying degrees causing myocyte necrosis, calcification, interstitial fibrosis, atrial muscle bundles disorganization, and so atrial fibrosis ${ }^{[24]}$.

MS is one of many disorders associated with LA remodeling and dilation. Two broad conditions are responsible for LA enlargement: pressure and volume overload ${ }^{[20,25]}$. In rheumatic MS, there is a wide range in which LA pressure exists, despite the similarity of MVA; because of the LA compliance which is a valuable determinant of LA pressure ${ }^{[26]}$. In rheumatic MS, there are different grades of LA compliance depression and variability in LA stiffness despite their similar MV area ${ }^{[27]}$. Lee et al, ${ }^{[28]}$ explained that by the fact of ultra-structural pathological findings did not correlate with the severity of MS and they reported that pathological alterations of myocardial ultrastructure were related to the extent of myocardial involvement by the rheumatic process rather than being structural adaptations in response to the hemodynamic derangement.

One of the main findings in this study is prolongation of the interatrial EMD in MS patients compared with control subjects $(p<$ 0.001 ).

These findings come in agreement with the results of Özer et al, ${ }^{[3]}$ who stated that interatrial EMD gets longer in MS patients group compared with control healthy subjects. Also, Demirkan et al, ${ }^{[11]}$ found that patients with moderate to severe MS had longer interatrial conduction time as compared to control subjects.

$\boldsymbol{P B M V}$ is the procedure of choice in management of rheumatic MS and it has very good immediate and long-term results in patients with suitable mitral valve morphology but those who have less suitable anatomy may still achieve adequately good symptomatic and hemodynamic response ${ }^{[29]}$. Although there are no data from comparative studies, PBMV is estimated to reduce the incidence of $\mathrm{AF}^{[30]}$. PBMV is the preferred treatment for symptomatic patients with moderate to severe MS and favorable anatomical findings without left atrial thrombus or significant mitral regurgitation ${ }^{[12]}$.

Our findings after one week from the valvuloplasty reflect mitral valve afterload reduction by the highly significant increase in mitral valve area and LAEF, while there were highly significant decline in mean and peak mitral valve gradients, LAD and pulmonary systolic pressure $(p<0.001)$.

Our results come in agreement with Vieira et al, ${ }^{[31]}$ who said that following PBMV; the decline in the MV afterload and the main acute impact on the LA were expressed by an increase in the MVA, a decline in mean and peak mitral valve gradients, a decline in the LA antero-posterior diameter and a decline in SPAP.

Also, these results come in agreement with Morttada et al, ${ }^{[32]}$ who assess the impact of successful PBMV with a significant increase in the mitral valve area, decrease in the pressure gradient across the mitral valve and decrease in SPAP leading to a decrease in left atrial pressure, pulmonary venous congestion and pulmonary artery pressure.

One week after $P B M V$, we documented a highly significant improvement in all LA indices (LAA max, LAV ${ }_{\text {max }}$, Ind. LAV max and Ind. LAV min $)$. We documented a highly significant reduction in the Ind. $\mathrm{LAV}_{\text {max }}$ by $21.8 \%(p<0.001)$.

These findings come in agreement with Antonini et al, ${ }^{[33]}$ who considered that LA reverse remodeling following PBMV, occurred when the Ind. LAV max reduced by > 15\%, as described previously for LA analysis after surgical repair of the mitral valve.

Also, in agreement with Adavane et al, ${ }^{[34]}$ who found that the Ind. LAV max reduced immediately after PBMV by $14.2 \%$ and reduced by $23.2 \% 30$ days after PBMV. In another study, the Ind. LAV $\max$ reduced by $16 \%$ at $72 \mathrm{~h}$ and by $21.5 \% 12$ months after PBMV.

We found highly significant increase in LAEF and LAEI one week after PBMV $(p<0.001)$, indicating improvement in the LA reservoir function, these results are not agreed with Pritchett et al, ${ }^{[35]}$ who stated that assessing atrial mechanical function by measuring volumes is time-consuming and depends on age, gender, and BSA.

We documented a highly significant decrease in P-max and PWD $(p<0.001)$ one week after PBMV.

These findings are in agreement with Turhan et al, ${ }^{[36]}$ who demonstrated decrease in P-max and PWD, which were regarded as ECG signs of the susceptibility to AF in both the short and long terms after PBMV.

One week after PBMV, regarding the interatrial $E M D$, there was a highly significant decrease in interatrial EMD using TDI $(p<0.001)$. 
This result is in agreement with that of Demirkan et al, ${ }^{[11]}$ who studied the interatrial EMD before and 72 hours after valvuloplasty, and they explained this by the immediate decline in LA stretch (as a result of the immediate drop in LA pressure), also in their study both LA diameter and LA volume were decreased significantly after PBMV.

Finally, we found that interatrial EMD significantly correlated positively with LAD and showed positive association with LAA, these findings come in agreement with Özer et al, ${ }^{[3]}$ who showed that LA area and size are positively correlated with interatrial EMD in patients with MS.

In our study, we found highly significant positive correlation between echocardiographic interatrial EMD and both electrocardiographic $\mathrm{AF}$ markers (P-max and PWD) $(p<0.001)$.

Our findings come in agreement with Özer et al, ${ }^{[3]}$ who used this TDI method for investigating interatrial EMD in patients with MS, they detected a positive correlation between interatrial EMD and LA size, as well as between interatrial EMD and electrocardiographic AF markers (P-max and PWD).

\section{STUDY LIMITATIONS}

Adding to the small sample size, we have some limitations in this study. We did not have long-term follow-up data. Therefore, the relationship between these parameters and the development of AF is not clearly known. Moreover, our patients were relatively young and had somewhat lower Wilkins scores. Therefore, our results might not be applicable to all patients with MS who have more severe disease with higher Wilkins scores, patients of relatively advanced age or patients who have more inflammatory response. More studies should be carried out to study the relationship between these parameters and the incidence of AF.

\section{CONCLUSIONS}

This study shows that interatrial EMD is longer in patients suffered from moderate to severe MS compared to control group and is positively correlated with $\mathrm{PWD}$, which consider a marker of AF for such patients. Also, PBMV has a favorable effect on atrial conduction properties evaluated with both TDI echocardiography and ECG.

These parameters which are measured easily in the clinical practice are useful in the evaluation of atrial function, and also in AF prediction.

\section{ACKNOWLEDGEMENT}

We thank the patients for their kind participation in our study.

\section{REFERENCES}

1. Feinberg WM, Blackshear JL, Laupacis A, Kronmal R, Hart RG. Prevalence, age distribution, and gender of patients with atrial fibrillation. Analysis and implications. Arch Intern Med 1995; 155:469-73.

2. Can I, Onat AM, Aytemir K, Akdogan A, Ureten $\mathrm{K}$, Kiraz S, et al. Assessment of atrial conduction in patients with scleroderma by tissue Doppler echocardiography and $\mathrm{P}$ wave dispersion. Cardiology 2007; 108:317-321.

3. Özer N, Yavuz B, Can I, Atalar E, Aksöyek S, Övünç K, et al. Doppler tissue evaluation of intra-atrial and interatrial electromechanical delay and comparison with $\mathrm{P}$-wave dispersion in patients with mitral stenosis. J Am Soc Echocardiogr 2005; 18:945-948.

4. Chen CR, Cheng TO. Percutaneous balloon mitral valvuloplasty by the Inoue technique: a multicenter study of 4832 patients in China. Am Heart J 1995; 129:1197-203.

5. Reyes VP, Raju BS, Wynne J, Stephenson LW, Raju R, Fromm BS, et al. Percutaneous balloon valvuloplasty compared with open surgical commissurotomy for mitral stenosis. $N$ Engl J Med 1994; 331(3):961-7.

6. Wright DJ, Willian SG, Tzeng BH, Marshall P, Mackintosh AF, Tan LB. Does balloon mitral valvuloplasty improve cardiac function? A mechanistic investigation into impact on exercise capacity. Int $J$ Cardiol 2003; 91(1):81-91.

7. Wilkins GT, Weyman AE, Abascal WM, Block PC, Palacios IF. Percutaneous mitral balloon valvulotomy: an analysis of echocardiographic variables related to outcome and the mechanism of dilatation. Br Heart $J$ 1988; 60:299-308.

8. Blume GG, Mcleod CJ, Barnes ME, Seward JB, Pellikka PA, Bastiansen PM, et al. Left atrial function: physiology, assessment, and clinical implications. Eur $J$ Echocardiogr 2011; 12:421-30.

9. Wang M, Lau CP, Zhang XH, Siu CW, Lee $\mathrm{KL}$, Yan $\mathrm{GH}$, et al. Interatrial mechanical dyssynchrony worsened atrial mechanical function in sinus node disease with or without paroxysmal atrial fibrillation. J Cardiovasc Electrophysiol 2009; 20:1237-43.

10. Yoon YE, Kim HJ, Kim SA, Kim SH, Park $\mathrm{JH}$, Park KH, et al. Left atrial mechanical function and stiffness in patients with paroxysmal atrial fibrillation. J Cardiovasc Ultrasound 2012; 20:140-5.

11.Demirkan B, Guray Y, Guray U, Ege MR, Kisacik HL, Sasmaz H, et al. The acute effect 
of percutaneous mitral balloon valvuloplasty on atrial electromechanical delay and $\mathrm{P}$-wave dispersion in patients with mitral stenosis. Herz 2013; 38:210-215

12.Bonow RO, Carabello BA, Chatterjee K, de Leon AC Jr, Faxon DP, Freed MD, et al. American College of Cardiology/American Heart Association Task Force on Practice Guidelines. 2008 focused update incorporated into the ACC/AHA 2006 guidelines for the management of patients with valvular heart disease: a report of the American College of Cardiology/American Heart Association Task Force on Practice Guidelines (Writing Committee to revise the 1998 guidelines for the management of patients with valvular heart disease). Endorsed by the Society of Cardiovascular Anesthesiologists, Society for Cardiovascular Angiography and Interventions, and Society of Thoracic Surgeons. J Am Coll Cardiol 2008; 52:e1e142.

13.Daubert JC, Pavin D, Jauvert G, Mabo P. Intra and interatrial conduction delay: implications for cardiac pacing. Pacing Clin Electrophysiol 2004; 27:507-25.

14.Kannel WB, Abbott RD, Savage DD, McNamara PM. Epidemiologic features of chronic atrial fibrillation: the Framingham study. N Engl J Med 1982; 306:1018-1022.

15.Garcia MJ, Rodriguez L, Ares M, Griffin BP, Klein AL, Stewart WJ, et al. Myocardial wall velocity assessment by pulsed Doppler tissue imaging: characteristic findings in normal subjects. Am Heart J 1996; 132(3):648656.

16. Yagmur J, Yetkin O, Cansel M, Acikgoz N, Ermis N, Karakus Y, et al. Assessment of atrial electromechanical delay and influential factors in patients with obstructive sleep apnea. Sleep Breath 2012; 16(1):83-8.

17.Krishnamoorthy KM, Dash PK, Dora S. P Wave Dispersion after Balloon Mitral Valvuloplasty. Indian heart joumal.org/SeptOct. 2003/abstract /335.

18.Krasuski RA, Assar MD, Wang A, Kisslo KB, Pierce C, Harrison JK, et al. Usefulness of percutaneous balloon mitral commissurotomy in preventing the development of atrial fibrillation in patients with mitral stenosis. Am J Cardiol 2004; 93:936-939.

19.John B, Stiles MK, Kuklik P, Chandy ST, Young GD, Mackenzie L, et al. Electrical remodeling of the left and right atria due to rheumatic mitral stenosis. Eur Heart J 2008 29:2234-2243.
20. Abhayaratna WP, Seward JB, Appleton CP, Douglas PS, Oh JK, Tajik AJ, et al. Left atrial size: physiologic determinants and clinical applications. $J$ Am Coll Cardiol 2006; 47:2357-63.

21.Inaba Y, Yuda S, Kobayashi N, Hashimoto A, Uno K, Nakata $T$, et al. Strain rate imaging for noninvasive functional quantification of the left atrium: comparative studies in controls and patients with atrial fibrillation. $J$ Am Soc Echocardiogr 2005; 18:729-36.

22.Tsang TS, Abhayaratna WP, Barnes ME, Miyasaka Y, Gersh BJ, Bailey KR, et al. Prediction of cardiovascular outcomes with left atrial size: is volume superior to area or diameter? J Am Coll Cardiol 2006; 47:101823.

23.Tsang TS, Barnes ME, Bailey KR, Leibson CL, Montgomery SC, Takemoto Y, et al. Left atrial volume: important risk marker of incidence atrial fibrillation in 1655 older men and women. Mayo Clinic Proc 2001; 76:46775.

24.Ozdemir AO, Kaya CT, Ozcan OU, Ozdol C, Candemir B, Turhan S, et al. Prediction of subclinical left ventricular dysfunction with longitudinal two-dimensional strain and strain rate imaging in patients with mitral stenosis. Int J Cardiovasc Imaging 2010; 26: 397-404.

25.Kennedy JW, Jarnall SR, Murray JA, Figley MM. Quantitative angiocardiography. IV. Relationships of left atrial and ventricular pressure and volume in mitral valve disease. Circulation 1970; 41:817-24.

26.Kapoor A, Kumar S, Shukla A, Tewari S, Garg $\mathrm{N}$, Goel P, et al. Determinants of left atrial pressure in rheumatic mitral stenosis: role of left atrial compliance and 'atrial stiffness'. Indian Heart J 2004; 56:27-31.

27.Caso P, Ancona R, Di Salvo G, Comenale Pinto S, Macrino M, Di Palma V, et al. Atrial reservoir function by strain rate imaging in asymptomatic mitral stenosis: prognostic value at 3 year follow-up. European Journal of Echocardiography 2009; 10:753-759.

28.Lee YS, Lee CP. Ultrastructural pathological study of left ventricular myocardium in patients with isolated rheumatic mitral stenosis with normal or abnormal left ventricular function. Jpn Heart J 1990; 31: 435-48.

29.Fawzy ME. Mitral balloon valvotomy, longterm results, its impact on severe pulmonary hypertension, severe tricuspid regurgitation, atrial fibrillation, left atrial size, left ventricular function. The Egypt Heart J 2014; 66:133-138. 
30.Fawzy ME, Shoukri M, Al Sergani H, Fadel B, Eldali A, Al Amri M, et al. Favorable effect of balloon mitral valvuloplasty on the incidence of atrial fibrillation in patients with severe mitral stenosis. Catheter Cardiovasc Interv 2006; 68:536-541.

31.Vieira ML, Silva MC, Wagner CR, Dallan LA, Kajita LJ, Oliveira WA, et al. Left atrium reverse remodeling in patients with mitral valve stenosis after percutaneous valvuloplasty: a 2- and 3-dimensional echocardiographic study. Rev Esp Cardiol (Engl Ed). 2013; 66(1):17-23.

32.Morttada A, ElFiky A, Onsy A, Samir S, Toema G. Echocardiographic effect of successful balloon mitral valvuloplasty on right ventricular function. The Egypt Heart $J$ 2015; 67:33-39.

33.Antonini-Canterin F, Beladan CC, Popescu BA, Ginghina C, Popescu AC, Piazza R, et al.
Left atrial remodeling early after mitral valve repair for degenerative mitral regurgitation. Heart 2008; 94:759-64.

34.Adavane S, Santhosh S, Karthikeyan S, Balachander J, Rajagopal S, Gobu P, et al. Decrease in left atrium volume after successful balloon mitral valvuloplasty: an echocardiographic and hemodynamic study. Echocardiography 2011; 28:154-160.

35.Pritchett AM, Jacobsen SJ, Mahoney DW, Rodeheffer RJ, Bailey KR, Redfield MM, et al. Left atrial volume as an index of left atrial size: a population-based study. $\mathrm{J}$ Am Coll Cardiol 2003, 41:1036-43.

36.Turhan H, Yetkin E, Senen K, Yilmaz MB, Ileri M, Atak R, et al. Effects of percutaneous mitral balloon valvuloplasty on P-wave dispersion in patients with mitral stenosis. Am J Cardiol 2002; 89:607-9. 